\title{
Democratizing Tech Giants! A roadmap
}

\author{
Hans Gersbach ${ }^{1}$
}

Received: 4 November 2019 / Accepted: 14 September 2020 / Published online: 22 October 2020

() The Author(s) 2020

\begin{abstract}
How society should deal with the self-strengthening Tech Giants is a much-discussed issue. We suggest to democratize them by giving users a say in their decisions. With newly-developed collective decision rules and user councils, democratization of Tech Giants becomes feasible and complements, e.g., competition and basic data protection laws.
\end{abstract}

Keywords Tech Giants · Democratization · Assessment Voting · Co-Voting · User councils

\section{Self-strengthening monopolies}

For better or worse, we daily contribute to powerful monopolies: We use products of the world's largest technology companies-Apple, Google, Microsoft, Facebook and Amazon. ${ }^{1}$ The more of us are using them, the more useful they become to us. Several further aspects make this type of monopoly self-strengthening (see e.g. Müller and Wambach (2018); Crémer et al. (2019)).

First, if an internet service like Google attracts more users, its search results become more relevant and its algorithms more refined, which makes it more attractive for individual users and thus for advertising companies-so that Google reaps more benefits.

Second, many of the services offered by so-called "Tech Giants" are free of charge for the individual customers, thus heightening incentives to join and use these services. The growing number of users allows to demand higher prices for advertising on theses services. Of course, the users pay for the services without noticing it, by paying attention to advertisement and by contributing to valuable databases.

\footnotetext{
${ }^{1}$ We note that ownership structures are more complicated. Alphabet owns Google, for instance. Moreover, the set of Tech Giants must not be limited to these five companies, as social media like Twitter might be included as well.
}

Hans Gersbach

hgersbach@ethz.ch

1 CER-ETH - Center of Economic Research at ETH Zurich and CEPR, ETH Zurich,

Zürichbergstrasse 18, 8092 Zurich, Switzerland 
Third, for those services and products we do have to pay, the positive network effects entail better products. As so many people use Microsoft products, for example, these products are more likely to be improved constantly, and the programming of any new (external) application will ensure its being compatible with Microsoft products. This, in turn, will attract more consumers and reinforce Microsoft's monopoly.

Fourth, although Tech Giants also face competition for services and products, their monopoly manifests itself in various forms. Amazon offers a wide range of products. This makes it attractive to buyers and sellers, but also relegates competitors to "niche products", on a smaller scale. Apple has built up such an impressive reputation for innovative, attractive "must-have" design and the flair of innovation in functionalities that customers are practically addicted to its products.

Fifth, thanks to their economic power, Tech Giants can buy competitors and innovative startups, or discourage them, and while a few years ago, we were using Tech Giants by choice, we are now trapped into using them for want of equivalent alternatives.

\section{Risks for democracy}

Thus, Tech Giants can become an economic threat-a monopoly generally entailing higher costs and limited choice for users/buyers in the long run. What is more, the Tech Giants control important information processes and platforms for spreading information, which are the basis for collective decision-making. Information spreading, information storing, access to information, information comparison, information weighting and information disregard, all are monitored by the Tech Giants.

Are these activities a risk or even a threat to democracy? To answer this question, let us start from some core principles on which well-founded democracies rely and which might be affected by Tech Giants. Parties or their candidates compete for the legislative and executive branches in free and anonymous elections. Voters have access to all relevant information to judge the performance and behavior of members of parliament and of the executive body. Free speech and freedom of the press ensure that this is indeed materialized at the best-possible level. Separation of powers and checks and balances ensure that no branch of government can enlarge its power beyond the boundaries specified in the constitution. Governmental power is limited and, in particular, the individuals' private sphere is protected from governmental intervention as long as the citizens do not violate the rules severely.

There are several areas in which Tech Giants might limit the functioning of these principles. First and most obviously, if a Tech Giant operates a platform on which a large amount of social interaction and communication takes place, it may limit free speech and communication among citizens.

Facebook is a good example for this duplicity and the challenges it entails. In a first phase, it advertised itself as promoting democracy: all opinions were to be considered equal and were given the same chance of being acknowledged, discussed, and promoted. Such was the argument against the monitoring of contents. When it 
became evident that this equality promoted anti-democratic forces and benefitted destructive, anti-social groups, the necessity for some kind of control and intervention led to a type of monitoring that came dangerously close to censoring. The middle course is still to be defined. It has to be free speech, with some dangerous areas and defamatory entries censored, for instance.

Second, the deep knowledge of Tech Giants about users-involving their behavior, opinions and revealed preferences, and sometimes entire personal profilesdevelops a power on the private sphere that is unprecedented and can be significantly higher than the power held by the state. While this information has been given voluntarily, it may become a constraint, and hurt individuals as citizens in democracy. This is most obvious when such data are given away to third parties or even to political parties and interest groups which then might use these personal data to try and influence citizens. ${ }^{2}$ Even more serious events would occur if personal data get into the wrong hands and are used to blackmail citizens to behave or vote in a particular way.

Third, even if Tech Giants remain passive and no personal data leave them, citizens are confronted with difficult and unwelcome situations. Having such an amount of personal data about citizens in the hand of a monopoly may lead to temptations to use them to influence voters towards preferences the owners of the Tech Giants have. This can be achieved in subtle ways through the recommendation system and information transmissions. If persons watching videos on the current status of security in the streets from time to time constantly receive recommendations for videos about proposals from extreme law and order parties, it may influence them. One day, a Tech Giants may simply start a campaign on an issue and assume a power to influence public opinion that is unprecedented. If everybody is aware of this possibility, it may impact politics even without any action from the Tech Giants.

Even if Tech Giants remain passive and have no intention to manipulate the users, the algorithms for search and recommendations, for instance, may have intrinsic biases that are not easy to detect from the outside and which may persist for a long time.

Fourth, Tech Giants play a role in the infrastructure for elections. Most obviously, if electronic voting takes place, it can rely on operating systems of the Tech Giants. Moreover, political campaigns use the platforms of Tech Giants. These functions increase the Tech Giants' power.

Several of the risks discussed above can be avoided and one can count on enlightened and critical citizens as well as on a free press and a state who is obliged to ensure free and fair elections to mitigate these risks. However, these risks are too large and threatening, such that the joint economic and potential political power of the Tech Giants has to be limited.

Of course, Tech Giants offer a wide range of services and products, and compete with each other on some of them. Moreover, not all services are problematic for democracy. Cloud computing services, for instance, are a lesser concern for competition and democracy than social media.

\footnotetext{
${ }^{2}$ Hoferer et al. (2020) make an assessment of the value of microtargeting in campaigns.
} 


\section{What to do?}

Many solutions are currently discussed and there seems to be no easy way to deal with the Tech Giants, even if standard tools of competition have been applied successfully to limit economic power (see Caffarra et al. 2018). ${ }^{3}$ Vigilant merger control or even the breaking up of Tech Giants offering many services might help, but may merely entail new Tech Giants. And even if regulations had supranational force-and were effective as globally as the Tech Giants-they would still have to keep pace with the Tech Giants' speed of innovation. In particular, time-consuming deliberation and decision processes render democracies far less able to monitor the Tech Giants' monopolies than non-democratic countries like China.

Moreover, big tech firms can dominate in their eco-systems. They accumulate personal data, set rules of conduct and may exclude participants who allegedly "misbehave". Such power goes way beyond standard market power and necessitates other approaches.

The best way to monitor the Tech Giants is via the "currency in which customers buy services"- the personal data (Economist 2018). Such control could operate in two directions: One could develop specific supranational laws governing the ownership and exchange of data and monitor the Tech Giants through these laws. Yet, such a legal system might be costly and too slow-again.

But the monitoring could also happen the other way round, by democratization instead of coercion. Our idea is to find solutions in which the Tech Giants and users play an active part. We develop new collective decision procedures that can be used for experimenting, and our monitoring problem with the Tech Giants would be an ideal field of experimentation (Gersbach et al. 2019; Gersbach 2017).

We suggest to let the users have a say in matters that are crucial for them. The first challenge is to know on which decisions the users should be consulted-it might be reasonable to start with important decisions of the shareholders that affect the users' right to their shared information. Moreover, users should have a say in general specifications for search and learning algorithms, for instance, and on user access and censoring rules. How should the users be given a voice? We present two basic ways how this could be organized.

\section{Solution: voting}

A first area in which to look for solutions are voting procedures. While a voting among all users is conceivable, more efficient voting procedures in the spirit of Co-voting might be more suitable (Gersbach 2017). With Co-voting, a randomlyselected representative subgroup of all users would be selected-a so-called "Assessment Group". The Assessment Group would vote first and the result

\footnotetext{
3 See in Crémer et al. (2019) how competition policy could be reshaped in the digital era.
} 
would be made public. The decision would be aggregated with the subsequent decision of the shareholders or their delegates in the Board of Directors to yield the final decision. The two voter-groups' decisions could be weighted according to a pre-defined key. This way to let the users be represented and be allowed to have a say in any important decision would certainly change these users' attitude towards the Tech Giants - they might even be able to better accept and support a difficult or costly decision. In turn, such involvement of users might help to protect the data ownership rights and ensure that algorithms are respecting free speech, as well as other desirable properties of information provision and dissemination.

Several variants of such voting procedures are conceivable. For instance, the voting process does not take place sequentially, but simultaneously, and the two decisions of the shareholders and the users-suitably weighted-yield the final decision. Furthermore, for issues of highest importance, one could imagine that the entire pool of users should have a say. For such cases, one could use Assessment Voting (see Gersbach et al. 2019). Under such voting procedures, once the Assessment Group has made a decision and the decision has been made public, the entire pool of users would have a chance to vote, either confirming the Assessment Group's decision by abstaining, reinforcing the result, or overturning the Assessment Group's outcome. Again, subsequently, the voting outcomes of the users and the shareholders, suitably weighted, would be aggregated to yield the final decision.

Of course, any voting procedure requires an assignment of voting rights to users. The simplest way would be to grant one vote per user. Yet, a more refined voting right assignment would be to relate a user's intensity of usage to the voting power granted for important decisions, including, but not limited to, the right to put initiatives to vote, specific veto rights to counteract coordination of shareholders on speaking with one voice, or counterproposal rights for users.

\section{Solution: user council}

An alternative way to let users have a say in the Tech Giants' decisions is to select a representative user group, a user council, who acts as representative body for the pool of users. ${ }^{4}$ Various possibilities exist how co-determination can be structured with user councils. Any of these forms requires the assignment of different types of rights - consultation, veto and co-decision rights - to the user council on all matters that are relevant for users. With such rights, the user council starts systematic communication with the Board of Directors and can negotiate on all matters for which it

\footnotetext{
4 Some forms of this type of co-determination might resemble the German system of "Betriebsrat" (works council). Works council members are elected by the company workforce for a given term. They may also be appointed to the board of directors. This allows to reduce workplace conflicts by improving and systematizing communication channels and to increase the bargaining power of workers towards owners by means of legislation. See e.g. Freeman and Lazear (1996) for an early analysis and Hübler and Olaf (2015) for an account of the pros and cons of work councils.
} 
has veto or co-decisions rights. Typically, for decisions regarding the users' right to their own information, access rules for users and censoring rules, co-decision rights should be strong and comprise veto rights on particularly sensitive matters. Furthermore, some members of the user council could be elected to the Board of Directors to directly participate in the decisions and to ensure systematic communication between the owners and the user council.

We next discuss who should represent the users in these councils and how these representatives should be chosen. The most straightforward way to select representatives via election by other users, no matter which type of users they are. These would be the so-called "Representatives". Such an election could be conducted like normal works council elections, with candidates presenting themselves for an office term. However, since the global user pool is so large, a randomly selected user sample group could also select user representatives from a list of candidates.

The other issue is who should have the right to stand for election. Of course, a precondition is active participation and if services are costly, to be revenue-generating users. Ideally, one would like to have "Super-Users", "Expert Users" and "Regular Users" in the user council. The first are the users who have the highest usage frequency, the second the ones who have highest technology expertise, and the last are regular ("average") users. Ideally, the candidate pool is composed of these three subgroups of users, and one might even elect representatives of each subgroup separately. ${ }^{5}$ Such a user representatives group would be a perfect task force: With the leverage power of the Super-Users, the extended knowledge of the Expert Users and the legitimacy of the Regular Users, it would certainly have sufficient weight to mitigate the Tech Giants' monopoly.

\section{Implementation}

Of course, this is merely a first attempt to assess how to democratize Tech Giants. Several crucial issues await more detailed investigation. We start by providing a roadmap for some of the most pressing issues.

First, if one immediately reflects on the real-like applications of voting procedures, we have to specify who is allowed to make proposals that are put to the vote, i.e. who would decide when Co-voting should be triggered at all. While this could be captured in an amendment of the constitution of the Tech Giants, a user charter, it appears to be useful to grant the users the right to call a referendum.

Second, with voting and electing a user council, users may face the problem that shareholders coordinate on speaking with one voice, which makes it difficult to overturn such a decision. With user councils, this problem is alleviated by user representatives in the Board of Directors and by veto rights for the most sensitive matters. With voting, it may be important that users can decide first and the result be

\footnotetext{
5 In principle, Super-Users and Expert Users could be selected by the algorithms and measuring tools of the Tech Giants themselves. Yet, such measuring tools are susceptible to manipulation.
} 
made public. Then, it will be much more difficult for shareholders to take an opposing stance if the users' decision is clear-cut.

Third, for both voting and electing a user council, the Tech Giants have appropriate technological toolkits and thus, they may find it particularly easy to manage this type of process. One can expect them to invent and develop ways to organize such democratic processes efficiently, in a fair and transparent way. However, since they own the technologies, they may also be tempted to steer the voting processes in the direction that suits them best. Since there are many manipulation possibilities, it is necessary that users can monitor these processes or-even better-that voting and elections are executed by trusted third parties.

Fourth, if voting and elections for the user councils are based on a randomlyselected Assessment Group, the representability of this Assessment Group is central-in the technical sense of randomization and in the perception of the users. Only if a vast majority perceives the Assessment Group as representative, will the decision by this group be legitimate. This is already a delicate issue in a single jurisdiction, so it should be a substantial challenge for a global user pool.

Fifth, of course, users themselves can differ vastly regarding how Tech Giants should be steered. Hence, all significant user perspectives should be represented in the user council if this solution is envisioned. On the most sensitive matters such as censoring rules, appropriate minority protection may be necessary.

Sixth, democratized Tech Giants may evolve and may become an organization with further bodies such as an arbitral tribunal for conflict resolution. Hence, Tech Giants may evolve towards a virtual jurisdiction and assume more and more power to structure the users' life. Of course, such developments should be bridled by national jurisdictions and by the law of nations.

Seventh, since Tech Giants offer very different services, there is competition for some of these services, while others are less of a concern for democracy, so that democratizing is not equally pressing for each of the Tech Giants and for each type of services. Clearly, Google and Facebook would be the natural starting points for a democratization endeavor. Other Tech Giants or other large social media like Twitter could follow.

Eighth, and most importantly, how to get the firms to agree to participate? Let us explore ways how this could happen.

- The government imposes regulations and forces the Tech Giants to give users a say.

Imposing direct regulations that require to give users a say would be one option. While the example of work councils in Germany suggests that such regulations are feasible, such steps are unlikely to happen in the US where the Tech Giants are headquartered. Hence, one has to look for other ways to democratize Tech Giants.

- Tech Giants participate "voluntarily”.

Tech Giants have to comply with reinforced privacy and data protection laws and are under more and more scrutiny regarding their behavior and how they deal with the boundaries of free speech and the dissemination of false information. This was demonstrated for instance, by the hearings at the American Con- 
gress in July 2020. It was the first time that all four leaders of Facebook, Amazon, Google and Apple had to testify at the same time. The fact that they came to answer themselves instead of sending someone from the legal department shows the concerns of both politicians and regulators about the impact of Tech Giants on the economy and democracy, as well as the concerns of the Tech Giants about the risk to be subject to much tigher regulations and legal prosecution. It was obvious that the Tech Giants are struggling to define their responsibilities towards the public. An preemptive move of the Tech Giants to give the users a say might be a way for them to slow down attempts to regulate them more tightly, to break them up or to directly restrict their business.

- Users' initiative to obtain more rights

The users themselves have become more critical regarding the Tech Giants. This is evident in view of the public discussions in the US and the EU. For instance, the widespread reporting about the various law suits and antitrust cases against Tech Giants in Europe has stimulated a broader discussion on how to deal with the Tech Giants. Hence, it is conceivable that users organize themselves and demand more say in these companies. It could only be a matter of time until this starts.

Ninth, how to reconcile the method with the firms' profit motive? Of course, giving users a say in Tech Giants may impact profits. However, as with the work councils in Germany, giving users a say is just a further constraint the firm has to obey when it maximizes profits, like many other constraints firms have. Hence, democratizing Tech Giants and profit motives can be reconciled, but it may make Tech Giants pursue profit-maximizing less aggressively. Given the large profit opportunities described in the preceeding sections, however, those Tech Giants who democratize themselves best in the users' eyes might be more attractive, and may increase their profits in the medium run.

The method we propose could be applied equally well to non-profit organizations, as nothing hinges on whether the firm maximizes profits or has another objective function. If Tech Giants become non-profit organizations, our suggestion could and should still be applied, and may be given more weight in such organizations.

\section{Comparison}

There are many proposals how to deal with Tech Giants. They can be divided into three areas: First, the existing competition laws can be used to prevent acquisitions or even to break up Tech Giants. Second, one should assess how appropriate liability for Tech Giants can be established and third, how data ownership laws can be designed and implemented, following the new European General Data Protection Regulation. The general goal of this third element is to set basic standards for the collection and use of data by these platforms, to allow users to take control over their own data, and to ensure fair competition. This means that users should be able to control the collection and usage of their data at a more specific level. Ideally, users should be able to see which party has which data and how it is used. They 
should also be able to take their data with them if they choose to switch to another platform. This would also strengthen possible competitors. Finally, all user data should be protected from third parties.

Several proposals refine and extend the above three directions, putting different weights on different elements (see e.g. Sabeel Rahman 2018; Müller and Wambach 2018; Sitaraman 2018; Crémer et al. 2019; Motta and Peitz 2020).

Our proposal is complementary to these approaches in the following sense. Competition, liability and basic data protection laws are, of course, useful to tame the Tech Giants. However, beyond these laws, democratization can yield additional benefits for society. For instance, new rules on data ownership and data portability may be developed by user participation, and these rules could even be companyspecific. Giving users a say in Tech Giants opens up an adaptable framework that can reach the same goals as the regulation approach, and democratizing could be a far more flexible way to deal with other issues in the future. It would avoid the need to reach consensus in international treaties on the regulation of Tech Giants. Moreover, involving users for issues such as censoring rules, minority user protection, transparent governance rules of the Tech Giants' ecosystem, control and developing discrimination-free algorithms might exceed what can be achieved by laws, even if such laws could be agreed upon at the international level. Finally, democratizing might also be a way of making people more aware how Tech platforms operate, since a seat in a user council or being selected to vote provides incentives to acquire information about Tech Giants. This, in turn, would make user participation more effective, and users could play a much larger role in monitoring and compliance. ${ }^{6}$

To sum up, while competition, liability and data protection laws are useful to tame the Tech Giants, democratizing them might achieve significantly more, and would establish a completely new legitimation basis for Tech Giants.

\section{Costs and speed of proposed methods}

The costs and time needed to implement the proposed solutions, such as user voting and user councils, are important. The Tech Giants should not find it difficult to comply with the requirements for secure and efficient selection of users and for the implementation of voting or elections to the user council. There exist blueprints for voting methods such as Assessment Voting and Co-Voting (see Basin et al. 2018) that can be used as a starting point. The costs of such implementations would be small compared to the profits of the Tech Giants. Still, a variety of further considerations and costs has to be taken into account. Developing the rules how users have a say, producing proposals for user deliberation and setting up the deliberation process takes time. Moreover, one has to make sure that selection of users, voting

\footnotetext{
${ }^{6}$ Users might also wish to have a say in how content is regulated. Wikipedia has established a sophisticated set of rules to determine content and to resolve conflicts. Parallel rules could be developed for Tech Giants in the area of Social Media, taking, of course, the different volume and speed of communication on such platforms into account.
} 
and election are transparent and verifiable for outsiders, which may necessitate that users or third parties are in control of such processes. Nevertheless, first steps in the democratization of Tech Giants could be taken within a few years.

\section{Conclusion}

New democratic procedures alone will not eliminate the monopoly of the Tech Giants, but they might re-balance the market by giving users some degree of decision power within this monopoly. If their monopoly is not endangered, the Tech Giants might be willing to share some of their power with users by including them into key decisions. This might be more efficient than bridling Tech Giants with regulations that cannot keep track with technological advances.

Lessening the Tech Giants' power to shape communication and data handling by including new democratic processes in their decision-making might even help to improve deliberation in democracy, since the separation of users in media ecosystems ${ }^{7}$ may be transcended (or lessened)—what a promising outlook for democracy!

Acknowledgements We would like to thank Moritz Hoferer and David Basin for helpful comments. First ideas have been presented in Gersbach (2019).

Funding Open access funding provided by Swiss Federal Institute of Technology Zurich.

Open Access This article is licensed under a Creative Commons Attribution 4.0 International License, which permits use, sharing, adaptation, distribution and reproduction in any medium or format, as long as you give appropriate credit to the original author(s) and the source, provide a link to the Creative Commons licence, and indicate if changes were made. The images or other third party material in this article are included in the article's Creative Commons licence, unless indicated otherwise in a credit line to the material. If material is not included in the article's Creative Commons licence and your intended use is not permitted by statutory regulation or exceeds the permitted use, you will need to obtain permission directly from the copyright holder. To view a copy of this licence, visit http://creativecommons.org/licen ses/by/4.0/.

\section{References}

Basin D, Radomirovic S, Lara S (2018) Alethea: a provably secure random sample voting protocol. IEEE 31st Computer Security Foundations Symposium, IEEE Press

Caffarra C, Latham O, Bennett M, Etro F, Régibeau P, Stillman R (2018) Google Android: European "Techlash" or milestone in antitrust enforcement? www.voxeu.org. Published 27 July 2018, retrieved September 30, 2019

Crémer J, de Montjoye Y-A, Schweitzer H (2019) Competition policy for the digital era: report. Publications Office of the European Union, Luxembourg

Economist (2018) How to tame the Tech Titans. https://www.economist.com/leaders/2018/01/18/how-totame-the-tech-titans. Accessed 19 Oct 2020

Freeman RB, Lazear EP (1996) An economic analysis of works councils. In: Rogers J, Streeck W (eds) Works councils: consultation, representation, and cooperation in industrial relations. University of Chicago Press, Chicago, pp 27-49

Gersbach H (2017) Co-voting democracy. Econ Govern 18(4):337-349

\footnotetext{
7 See Yochai et al. (2018).
} 
Gersbach H (2019) A bit of democracy for the Tech Giants: two ideas. www.voxeu. Retrieved October 2019

Gersbach H, Mamageishvili A, Tejada O (2019) The effect of handicaps on turnout for large electorates: an application to Assessment Voting. CEPR discussion paper DP13921

Hoferer M, Lucas B, Herrmann HJ, Gersbach H (2020) The impact of technologies in political campaigns. Phys A 538:122795

Hübler O (2015) Do works councils raise or lower firm productivity? IZA World of Labor 137. www.wol. iza.org. Retrieved October 14, 2019

Motta M, Peitz M (2020) Competitive effects of big tech mergers and implications for regulation. CEPR discussion paper no. 14353

Müller C, Wambach A (2018) Digitaler Wohlstand für alle. Campus, Frankfurt am Main

Sabeel Rahman K (2018) The new utilities: private power, social infrastructure, and the revival of the public utility concept. Cardozo Law Rev 39(5):1621-1689

Sitaraman G (2018) Regulating tech platforms: a blueprint for reform, the great democracy initiative. Vanderbilt law research paper no. 18-64. https://ssrn.com/abstract=3278418. Accessed August 20, 2020

Yochai B, Farris R, Roberts H (2018) Network propaganda: manipulation, disinformation, and radicalization in American politics. Oxford University Press, New York

Publisher's Note Springer Nature remains neutral with regard to jurisdictional claims in published maps and institutional affiliations. 